\title{
Pemberdayaan Wanita Tani Kabupaten Kudus dalam Pembuatan Saus Cabai (Capsicum anuum)
}

\section{Empowerment of Kudus Peasant Women to Produce Chili (Capsicum anuum) Ketchup}

\author{
Dyah Ayu Widyastuti ${ }^{1}$, Fafa Nurdyansyah ${ }^{2}$ \\ ${ }^{1}$ Pendidikan Biologi, Universitas PGRI Semarang \\ ${ }^{2}$ Teknologi Pangan, Universitas PGRI Semarang \\ 11dyah.ayu@upgris.ac.id
}

Riwayat Artikel: Dikirim 12 Desember 2018; Diterima 7 Mei 2019; Diterbitkan 31 Mei 2019

\begin{abstract}
Abstrak
Produksi cabai (Capsicum anuum) di Kabupaten Kudus yang cukup melimpah belum banyak dimanfaatkan oleh masyarakat. Buah cabai dapat diolah menjadi produk saus sehingga meningkatkan nilai ekonominya. Pengolahan cabai menjadi saus cabai dapat meningkatkan nilai jual sekaligus menghindari pembusukan berlebih ketika musim panen. Pengolahan cabai ini juga dapat menjadi alternatif pemberdayaan wanita tani di Kabupaten Kudus sehingga keterampilan dan produktivitasnya meningkat. Program ini bertujuan untuk memberdayakan wanita tani di Kabupaten Kudus dalam pembuatan saus cabai demi meningkatkan produktivitas dan kesejahteraan ekonomi masyarakat. Pelaksanaan program dibagi menjadi tiga tahapan yaitu penyuluhan dan sosialisasi, pelatihan, serta monitoring dan evaluasi. Peserta pelatihan adalah ibu-ibu wanita tani Kabupaten Kudus yang cenderung tidak produktif. Antusiasme peserta pelatihan terlihat dari keterlibatan dan partisipasi mereka dalam setiap tahapan program. Peningkatan keterampilan pembuatan saus cabai melalui pemberdayaan wanita tani Kabupaten Kudus ini diharapkan dapat meningkatkan produktivitas dan tingkat ekonomi masyarakat yang selama ini bergantung pada sektor pertanian.
\end{abstract}

Kata kunci: pemberdayaan, saus cabai, wanita tani.

\begin{abstract}
The high production of chilli (Capsicum anuum) in Kudus is not utilized yet. Chilli can be processed to other products such as chilli ketchup so its economical value is increasing. Chilli processing to ketchup is improve its price and also inbibit putrefaction when in harvest time. Its chilli processing can also empower peasant women in Kudus so it would increase their skill and productivity. The aim of this program is to empower peasant women in Kudus to process chilli ketchup. The program is devide into three steps: counseling and socialization, training, also monitoring and evaluation. The participants are peasant women in Kudus whose productivity is not so high. The participants antusiasm showed in their involvements and partisipations in each steps. Productivity of society are expected to improve by empower Kudus peasant women to produce chilli ketchup. So, the economy level is also been increased by its empowering program.
\end{abstract}

Keywords: empowering, chilli ketchup, peasant women.

\section{PENDAHULUAN}

Kabupaten Kudus terletak di Provinsi Jawa Tengah yang memiliki lahan pertanian bukan sawah mencapai $17,77 \%$. Lahan pertanian bukan sawah tersebut dimanfaatkan oleh masyarakat untuk menanam jenis sayur mayur. Pada tahun 2014, cabai (Capsicum anuum) merupakan jenis yang paling banyak ditanam dan diikuti oleh bawang merah (BPS, 2015). Cabai banyak ditanam di Kabupaten Kudus untuk sekedar memenuhi kebutuhan rumah tangga masyarakat. Belum adanya keterampilan dalam peningkatan nilai ekonomi cabai menjadikan masyarakat hanya menjual cabai dalam bentuk tidak terolah.

Cabai merupakan jenis komoditas sayuran yang dapat dijadikan sebagai pilihan agribisnis (Asni \& Novalinda, 2010), sayangnya di Kabupaten Kudus belum banyak pengolahan cabai yang dilakukan. Padahal, olahan cabai memiliki nilai 
ekonomi cukup tinggi dalam industri mie, kecap, bumbu masak, maupun saus. Olahan buah cabai hasil pengolahan dapat dikonsumsi dalam bentuk bubuk kering maupun pasta/saus. (Nugrahani \& Hera, 2007).

Pengolahan cabai dapat menjadi
alternatif kegiatan pemberdayaan
masyarakat Kabupaten Kudus, terutama untuk wanita tani yang tidak setiap hari bekerja di sawah sehingga produktivitasnya dapat meningkat (Septia dkk., 2018). Keterampilan wanita tani Kabupaten Kudus untuk mengolah buah cabai berpotensi untuk meningkatkan pendapatan rumah tangga sehingga kesejahteraan pun akan meningkat (Nurdyansyah \& Widyastuti, 2017).

Keterampilan wanita tani di Kabupaten Kudus untuk mengolah cabai menjadi saus diharapkan dapat menguatkan perekonomian rumah tangga. Rumah tangga yang kuat perekonomiannya selanjutnya akan berdampak pada penguatan perekonomian masyarakat wilayah tersebut. Tujuan program ini adalah untuk meningkatkan keterampilan wanita tani di Kabupaten Kudus dalam mengolah buah cabai menjadi saus sehingga dapat meningkatkan nilai ekonominya.

\section{METODE}

Pelaksanaan program ini dibagi menjadi beberapa tahapan yang meliputi penyuluhan dan sosialisasi, pelatihan, serta monitoring dan evaluasi. Tahapan pelaksanaan tersebut adalah sebagai berikut:

a. Penyuluhan dan sosialisasi

Kegiatan penyuluhan dan sosialisasi dimaksudkan untuk membuka wawasan mengenai potensi buah cabai dalam bidang pangan, terutama untuk diolah menjadi saus cabai pelengkap sajian berbagai jenis makanan. Pada kegiatan penyuluhan dan sosialisasi ini juga dijelaskan mengenai tahapan pengolahan buah cabai menjadi saus secara singkat sebelum peserta dibekali dalam pelatihan pembuatan saus cabai.

b. Pelatihan

Pelatihan dilakukan dengan memberikan demonstrasi pembuatan saus cabai terlebih dahulu. Demonstrasi dimaksudkan agar peserta pelatihan memperoleh gambaran umum teknik pembuatan saus cabai dengan lebih jelas. Pada tahapan ini selanjutnya peserta pelatihan diberikan kesempatan untuk mengolah buah cabai menjadi saus. Pengolahan dilakukan secara sederhana agar dapat memanfaatkan peralatan rumah tangga yang dimiliki peserta di rumah.

c. Monitoring dan evaluasi

Kegiatan ini dilakukan untuk melihat kemampuan yang dimiliki oleh peserta setelah pelatihan pengolahan buah cabai menjadi saus. Evaluasi juga dilakukan untuk melihat seberapa besar peningkatan keterampilan peserta dalam meningkatkan nilai ekonomi buah cabai menjadi produk dengan nilai jual lebih tinggi.

\section{HASIL DAN PEMBAHASAN}

Pelatihan pengolahan buah cabai menjadi saus dilaksanakan di Aula Bidang Ketahanan Pangan, Dinas Pertanian dan Pangan, Kabupaten Kudus. Peserta pelatihan terdiri atas 20 orang wanita tani dari wilayah Kudus. Peserta pelatihan dibekali terlebih dahulu mengenai nilai penting cabai dan pengolahannya menjadi saus sehingga diperoleh wawasan dan gambaran baru mengenai olahan buah cabai.

Peserta mengikuti seluruh tahapan kegiatan dengan baik dan penuh antusiasme. Semua peserta berpartisipasi secara aktif dalam praktik pengolahan buah cabai menjadi saus, termasuk ketika diberikan penjelasan dan demonstrasi mengenai tahapan pengolahan saus cabai. Antusiasme peserta tersebut menunjukkan ketertariakan terhadap peningkatan keterampilan yang 
nantinya dapat mereka manfaatkan demi mendukung perekonomian keluarga.

Rangkaian kegiatan diawali dengan penyuluhan dan sosialisasi mengenai nilai guna buah cabai serta pengolahan buah cabai tersebut menjadi produk pangan yang memiliki nilai ekonomi lebih tinggi. Tahapan penyuluhan dan sosialisasi dipilih untuk dilakukan karena penyuluhan dan sosialisasi merupakan cara pelaksanaan program dengan prinsip alih teknologi dan diketahui paling efektif untuk pembelajaran bagi orang dewasa (Yanti \& Arlius, 2018). $\mathrm{Hal}$ tersebut terbukti dengan tingginya antusias peserta pelatihan.

Kegiatan pemberdayaan wanita tani di Kabupaten Kudus ini dapat menjadi alternatif peningkatan martabat dan kesejahteraan masyarakat agar terbebas dari jeratan keterbelakangan dan kemiskinan (Minarni dkk., 2017). Wanita tani banyak menghabiskan waktu di rumah ketika tidak sedang bekerja di sawah dan cenderung tidak produktif (Septia dkk., 2018). Oleh karena itu, potensi wanita tani dapat dioptimalkan melalui pemberdayaan dan peningkatan keterampilan, salah satunya dengan pelatihan pengolahan saus cabai.

Gambar 1.

Proses perebusan bahan pembuatan saus cabai

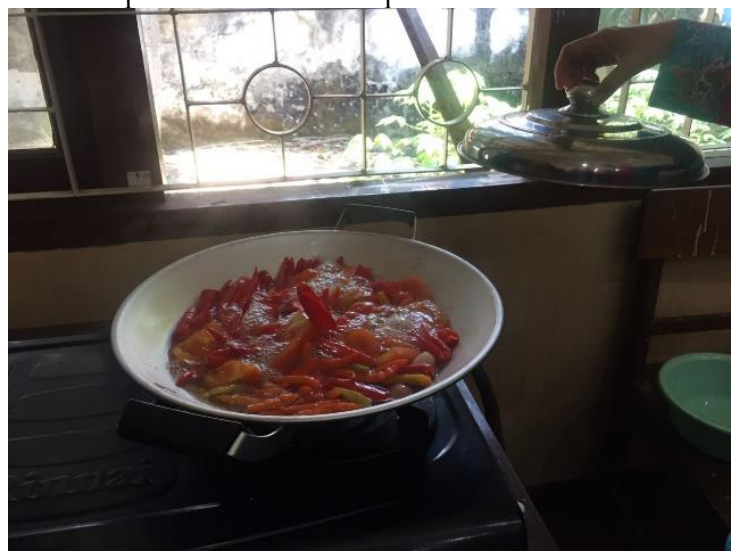

Bahan yang diperlukan dalam pembuatan saus cabai cukup sederhana dan mudah didapatkan oleh peserta pelatihan. Bahan utama yang diperlukan adalah cabai merah dan cabai rawit, tomat, ubi, dan tepung maizena. Garam dan gula ditambahkan untuk menambah cita rasa. Ubi yang digunakan dikukus terlebih dahulu sebelum dicampurkan ke adonan saus cabai. Ubi ini digunakan untuk menambah kekentalan saus, selain dengan penambahan tepung maizena.

Cabai merah, cabai rawit, dan tomat dicuci bersih kemudian direbus dengan air hingga lunak (Gambar 1). Proses perebusan dilakukan hingga bahan-bahan tersebut melunak sehingga mudah untuk dihaluskan. Bahan yang sudah lunak kemudian ditambah dengan ubi kukus dan dihaluskan dengan blender (Gambar 2). Penyaringan juga dilakukan untuk mengoreksi tekstur saus cabai agar menjadi lebih halus (Gambar $3)$.

\section{Gambar 2.}

Proses penghalusan semua bahan saus dengan

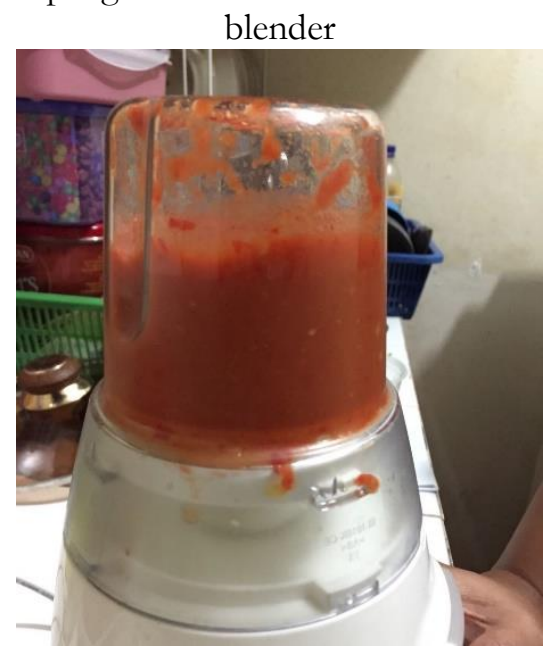

Gambar 3.

Bahan yang telah dihaluskan kemudian disaring agar tekstur saus cabai lebih halus

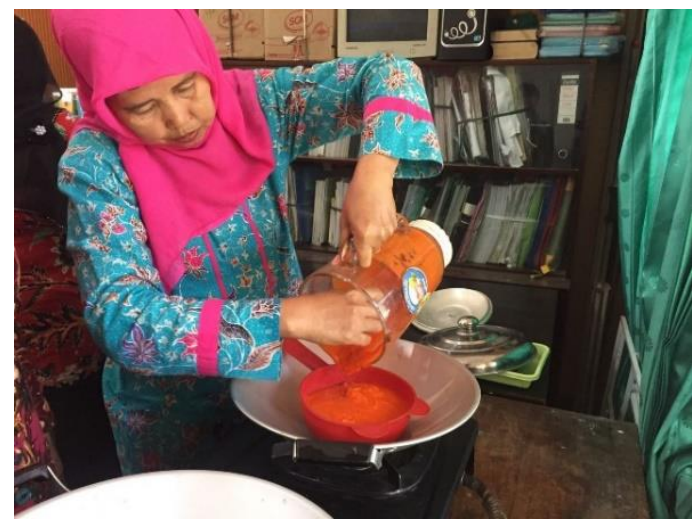


Saus sambal yang sudah dihaluskan dan disaring kemudian direbus kembali hingga matang sebelum dilakukan pengemasan. Pada proses perebusan tersebut, ditambahkan cuka dan tepung maizena. Saus cabai direbus hingga mencapai kekentalan yang diinginkan (Gambar 4). Saus cabai selesai dimasak setelah mendidih dan memiliki kekentalan yang sesuai. Produk olahan ini kemudian diturunkan suhunya terlebih dahulu sebelum dikemas dalam botol kaca (Gambar 5).

\section{Gambar 4.}

Peserta pelatihan antusias untuk merebus saus cabai hingga mengental

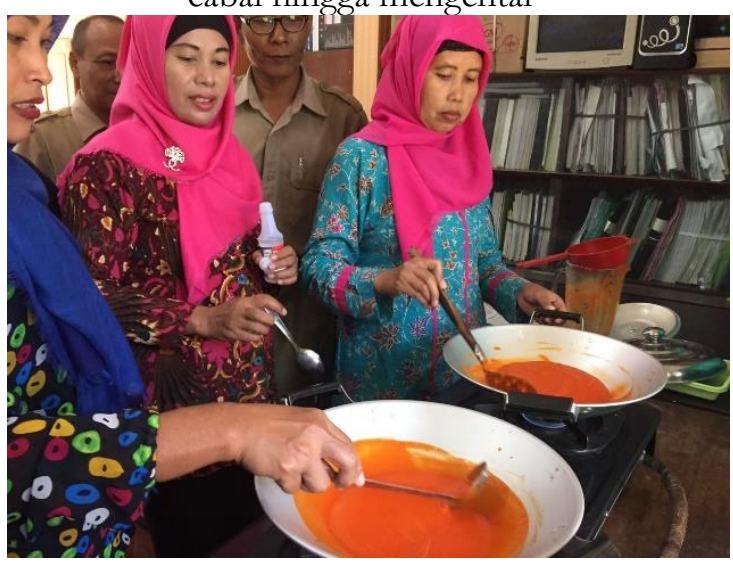

Gambar 5

Pengemasan saus cabai ke dalam botol kaca

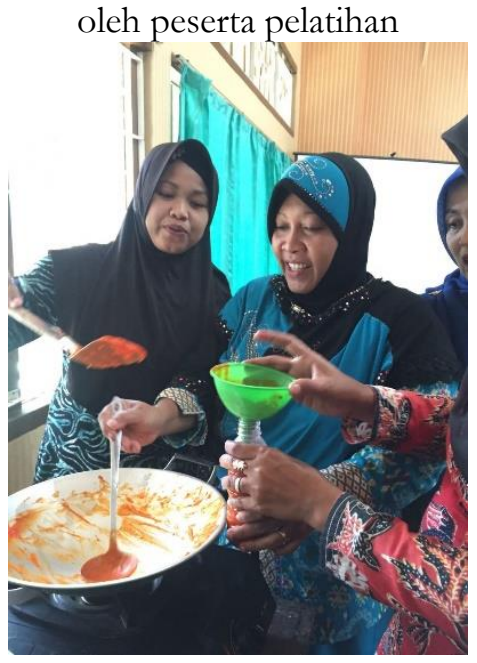

Pelatihan pengolahan buah cabai menjadi saus ini dapat meningkatkan keterampilan peserta pelatihan. Sebagian besar wanita tani yang mengikuti pelatihan tidak memiliki pekerjaan lain selain bekerja di sawah. Perekonomian keluarga mereka sangat bergantung pada hasil sawah yang terkadang tidak menentu akibat cuaca buruk maupun hama. Wanita tani ini hanya bekerja di sawah pada waktu-waktu tertentu, sehingga sehari-hari mereka ada di rumah dan cenderung kurang produktif. Keterampilan baru yang dipelajari melalui pelatihan ini diharapkan dapat membantu meningkatkan produktivitas peserta yang selanjutnya dapat bermanfaat untuk meningkatkan perekonomian keluarga masing-masing.

Pembuatan saun cabai ini harus memperhatikan beberapa hal, di antaranya $\mathrm{pH}$ adonan, total padatan terlarut, warna, rasa, serta kekentalan (Wandestri dkk., 2016). Oleh karena itu, peserta pelatihan juga diajarkan untuk menambah derajat keasaman $(\mathrm{pH})$ adonan saus dengan penambahan cuka masak, menambah kekentalan dengan penambahan ubi kukus dan tepung maizena, serta menyesuaikan perbandingan bahan terlarut dengan air untuk merebus. Semua faktor tersebut nantinya sangat berengaruh pada kualitas saus cabai yang dihasilkan. Peserta pelatihan juga dibekali dengan cara pemilihan bahanbahan yang baik untuk digunakan, maliputi penggunaan buah cabai dan tomat yang segar, ubi yang berwarna putih, serta pelarutan tepung maizena sebelum penggunaan. Semua keterampilan tersebut dapat dimanfaatkan oleh peserta pelatihan jika ingin membuka usaha produksi saus cabai di rumah masing-masing.

Respon peserta pelatihan sangat baik, terlihat dari antusiasme mereka dalam menerima semua arahan dari tentor serta keterlibatan secara langsung untuk ikut mengolah bahan menjadi produk saus cabai. Wanita tani peserta pelatihan juga tidak segan untuk bertanya apabila belum mengerti tahapan yang dijelaskan. Mereka juga menyampaikan bahwa keterampilan yang mereka pelajari sangat bermanfaat dan memacu untuk diaplikasikan dalam 
kehidupan sehingga dapat membantu peningkatan perekonomian keluarga mereka.

Proses pembuatan saus cabai ini sangat mudah dilakukan dengan alat dan bahan yang tersedia di dapur rumah tangga. Selain itu, potensi jumlah cabai di Kabupaten Kudus juga mendukung produksi saus cabai sehingga peserta dapat dengan udah mengaplikasikan keterampilan yang mereka dapat untuk diterapkan di rumah. Pada proses monitoring dan evaluasi, terlihat kemampuan peserta meningkat dalam pengolahan buah cabai menjadi saus, terlihat dari keterampilan mereka untuk menentukan perbandingan bahan secara tepat sehingga saus cabai yang diproduksi memiliki kualitas yang baik.

\section{KESIMPULAN}

Potensi wanita tani di Kabupaten Kudus dalam pengolahan bahan baku menjadi produk olahan pangan sangat besar. Wanita tani ini dapat diberdayakan untuk memproduksi buah cabai menjadi saus sehingga nilai ekonominya semakin meningkat. Keterampilan yang didapatkan oleh peserta pada pelatihan dapat dijadikan sarana untuk meningkatkan pendapatan rumah tangga sehingga kesejahteraan keluarga pun meningkat.

\section{DAFTAR PUSTAKA}

Asni, N. \& D. Novalinda. (2010). Teknologi pengolahan saus cabai berkualitas dan keamanan pangannya ditingkat petani provinsi jambi. Tersedia online https://fpdp.files.wordpress.com/20 17/02/sauscabe.pdf. Diakses pada 14 Desember 2018.

BPS. (2015). Kudus dalam Angka. Tersedia Online http://kuduskab.go.id/arsip/ pdf/kda2015.pdf. Diakses Pada 14 Desember 2018.

Minarni, E. W., D. S. Utami, \& N. Prihatiningsih. (2017). Pemberdayaan kelompok wanita tani melalui optimalisasi pemanfaatan pekarangan dengan budidaya sayuran organik dataran rendah berbasis kearifan lokal dan berkelanjutan. Jurnal Pengabdian dan Pemberdayaan Masyarakat, 1(2), 147-154.

Nugraheni, M. \& T. Hera. (2007). Peningkatan kapasitas dan kualitas produksi cabai merah kering dengan alat pengering sederhana di industri pangan dan rumah tangga (IPRT) Satrio Buwono Kecamatan Sanden Bantul. Tersedia online http://staffnew.uny.ac.id/ upload/132300107/pengabdian/upl oad-vucercabai02.pdf. Diakses pada 14 Desember 2018.

Nurdyansyah, F. \& D. A. Widyastuti. (2017). Pengolahan limbah air kelapa menjadi nata de coco oleh ibu kelompok tani di kabupaten kudus. Jurnal Kewirausabaan dan Bisnis, 21(11), 2230.

Septia, E. D., Windiana, L., \& Amir, N. O. (2018). Pemberdayaan Ibu Rumah Tangga Dengan Teknologi Budidaya Aquavertikulture Pada Lahan Sempit. CARADDE: Jurnal Pengabdian Kepada Masyarakat, 1(1), 30-35.

Wandestri, F. Hamzah, \& N. Harun. (2016). Penambahan beberapa konsentrasi xanthan gum terhadap mutu saos tomat (Solanum lycopersicum Lin.). Jom Faperta, 3(1), 1-9.

Yanti, D. \& F. Arlius. (2018). Pemberdayaan masyarakat tani melalui pengembangan teknologi biogas dengan pemanfaatan limbah pertanian sebagai sumber energi alternatif pedesaan. Jurnal Pengabdia Kepada Masyarakat, 24(1), 537-543. 